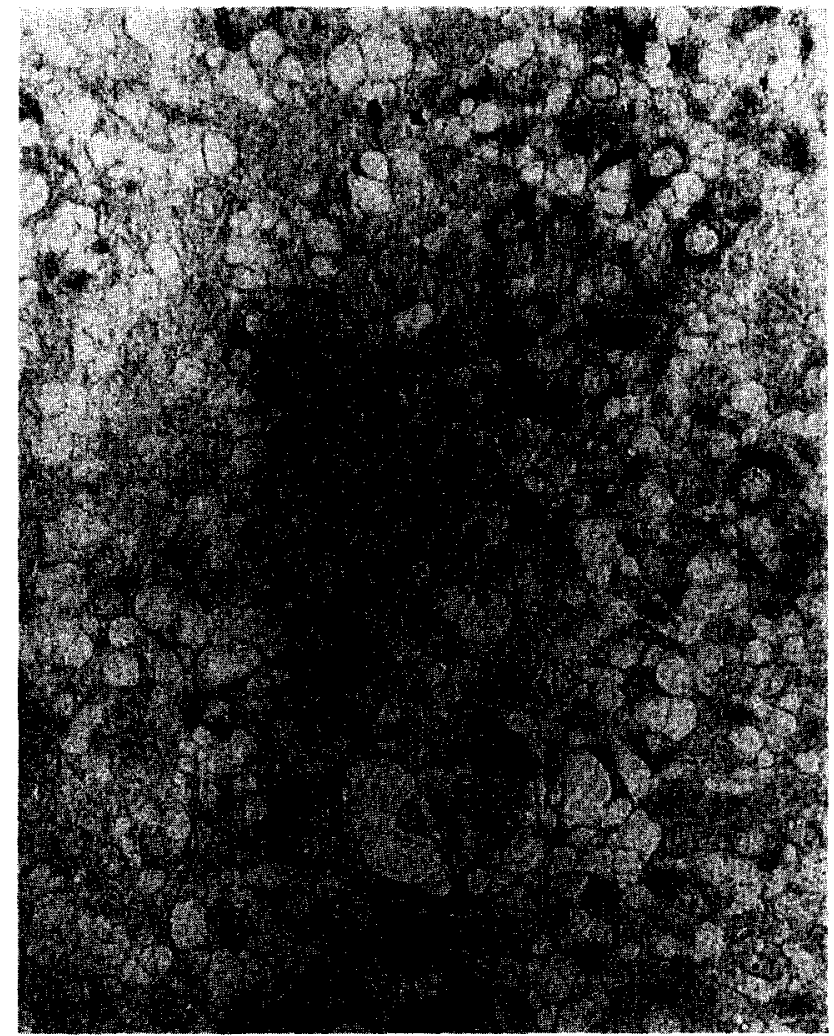

FICURE 3. Immunohistochemistry of the tumor. Glial fibrillary acidlc proteln is demonstrated only weakly and partially. (Irrmunoperoxidase stain; magnification $\times 550$.)

The microscopic features of myxopapillary ependymoma are distinctive: papillary or reticular pattern of growth of the tumor cells and an abundant mucinous stroma. The present tumor showed these characteristic features on the hematoxylin- eosin-stained sections, so distinction from other cercbral tumors was not difficult. Blepharoplasts were not demonstrated even by phosphotungstic acid-hematoxylin stain, but it is uncommon to find them. ${ }^{5}$ Immunohistochemically, this variant usually shows a strongly positive reaction with GFAP. The present tumor, however, exhibited only weak and sporadic positivity with GFAP, whereas vimentin was expressed intensely and throughout the tumor. This phenomenon may indicate that, despite the fairly characteristic and benign appearance, this tumor is functionally undifferentiated. ${ }^{9}$

Acknowledgment. The authors thank Michie Nakano and Shouichi Yamashita for their valuable help in preparing the histologic sections and in performing immunohistochemistry.

\section{REFERENCES}

1. Kernohan JW: Primary tumors of the spinal cord and intradural filum terminale, in Penfield W (ed): Cytology and Cellular Pathology of the Nervous System, vol 3. New York, NY, Paul B. Hoeber, 1932, pp 993-1025

2. Russell DS, Rubinstein LJ (eds): Tumors of central neuroepithelial origin, in Pathology of Tumours of The Nervous System (ed 5). London, UK, Edward Arnold, 1989, pp 203-206

3. Helwig EB, Stern J: Subcutaneous sacrococcygeal myxopapillary ependymoma: A clinicopathologic study of 32 cases. Am J Clin Pathol 81:156-161, 1984

4. Sato H, Ohmura K, Mizushima M, et al: Myxopapillary ependymoma of the lateral ventricle: A study on the mechanism of its stromal myxoid change. Acta Pathol Jpn 33:1017-1025, 1983

5. Sonneland PRI, Scheithauer BW, Onofrio BM: Myxopapillary ependymona: A clinicopathologic and immunocytochemical study of 77 cases. Cancer 56:883-893, 1985

6. Burger PC, Scheithauer BW, Vogel FS (eds): Brain: Tumors, in Surgical Pathology of the Nervous System and Its Coverings (ed 3). New York, NY, Churchill livingstone, 1991, pp 271-286

7. Burger PC; Scheithauer BW, Vogel FS (eds): Spinal meninges, spinal nerve roots and spinal cord: Ependyma, in Surgical Pathology of the Nervous System and Its Coverings (ed 3). New York, NY, Churchill Livingstone, 1991, pp 637-646

8. Mork SJ, Loken AC: Ependymoma: A follow-up study of 101 cases. Cancer 40:907-915, 1977

9. Caccamo DV, Herman MM, Rubinstein LJ: An immunohistochemical study of the primitive and maturing elements of human cerebral medulloepitheliomas. Acta Neuropathol 79:248-254, 1989

\title{
PROGESTERONE RECEPTORS IN BILATERAL OVARIAN EPENDYMOMA PRESENTING IN PREGNANCY
}

\author{
Kyle A. Ciarr, MD, James A. Roberts, MD, and Thomas S. Frank, MD
}

We present a case of a 25-year-old patient at term pregnancy who presented with a bilateral ovarian neoplasm that was histologically and immunohistochemically indistinguishable from ependymoma of the central nervous system. Progesterone receptors were detected in primary and recurrent neoplasms by immunohistochemistry. This is the first case of this rare neoplasm to present during pregnancy as well as with bilateral ovarian involvement. Together with a previously reported case of recurrent ovarian ependymoma with estrogen and progesterone receptors, this case suggests that hormonal responsiveness of this rare neoplasm may be pathogenically significant.

From the Departments of Pathology and Obstetrics and Gynecology, University of Michigan Medical School, Ann Arbor, MI. Accepted for publication December 18, 1991.

Key words: ovary, ependymoma, progesterone receptor, pregnancy. Address correspondence and reprint requests to Thomas S. Frank, MD, Department of Pathology, 2G332-0054, University Hospital, 1500 E Medical Center Dr, Ann Arbor, MI 48109-0054.

Copyright (c) 1992 by W.B. Saunders Company

$0046-8177 / 92 / 2308-0023 \$ 5.00 / 0$
HUM PATHOL 23:962-965. Copyright (C) 1992 by W.B. Saunders Company

In 1982 Aguirre and Scully reported five cases of malignant ovarian tumors composed primarily of neuroectodermal tissue. 'Two of their cases contained distinct foci of ependymal tissue. Kleinman et al subsequently reported three cases of unilateral ovarian tumors composed purely of fully differentiated ependymal tissue. ${ }^{2}$ One of these cases recurred while the patient was receiving postoophorectomy estrogen and progestin replacement therapy, and cytosolic assay of the recurrent tumor was positive for both estrogen and progesterone receptors. ${ }^{3}$ We report a case of a bilateral ovarian ependymoma with peritoneal spread, discovered incidentally at cesarean section, that stained positively for progestin receptors in both the primary and recurrent neoplasms.

\section{CLINICAL HISTORY}

The patient was a 25-year-old woman (gravida II, para 1001) at term, with a transverse lie requiring cesarean section. 
Her past obstetric, gynecologic, and general medical histories were unremarkable. At the time of operation she was found to have an ovarian tumor that was biopsied and reported as malignant. Three weeks later, at the University of Michigan Medical Center, the patient underwent a staging laparotomy that included a total abdominal hysterectomy, bilateral salpingo-oophorectomy, omentectomy, resection of the right diaphragm and upper right lobe of the liver, and ultrasonic aspiration of all the tumor implants larger than $1 \mathrm{~cm}$. The operative findings included 2 to $3 \mathrm{~L}$ of clear ascitic fluid, a $20 \times 20 \mathrm{~cm}$ right ovary, an $8 \times 16 \mathrm{~cm}$ left ovary, diffuse involvement by tumor of most peritoneal surfaces, and a 20 $\mathrm{cm}$ mass involving the right liver lobe and the diaphragm. At completion of this surgery, no tumor implant larger than 1 $\mathrm{cm}$ remained. The tumor was considered to be stage IV due to the liver involvement

The postoperative course was complicated by difficulty with pain control, a pneumothorax, a coagulopathy, and an episode of sepsis, all of which were successfully treated with medical management. The first course of chemotherapy was started on the 15 th postoperative day, and the patient was discharged home on the 17 th postoperative day.

She was given six courses of BEP chemotherapy $(100 \mathrm{mg} /$ $\mathrm{m}^{2}$ cisplatin and $100 \mathrm{mg} / \mathrm{m}^{2}$ etoposide plus an infusion of 15 $\mathrm{U} / \mathrm{d}$ bleonycin on days 1 to 3 ), which was colerated without complications, with the exception of a right subclavian vein thrombosis. Four weeks after receiving six courses of chemotherapy the patient underwent a second look laparotomy. Multiple, 1- to 4-mm implants of tumor were found throughout the peritoneal cavity and were biopsied. The patient experienced some bleeding from the dissection around the liver and developed a postoperative fever that responded to antibiotics. She was discharged home on the eighth postoperative day.

Due to the presence of the small residual disease, the patient was treated with whole abdominal radiation. She tolerated a dose of 2,560 centigray (cGy) to the abdomen, with kidney blocks placed at $1,760 \mathrm{cGy}$ and liver blocks placed at 2,060 cGy. The pelvis was boosted to a total dose of 4,472 cGy. This treatment was well tolerated, with only nausea and vomiting complicating the treatment. The patient is doing well approximately 1 year after the initial presentation (3 months after completing the radiation therapy). She did not receive replacement hormonal therapy at any time after the initial resection.

\section{MATERIALS AND METHODS}

Sections of neoplastic tissue were fixed in $10 \%$ neutral buffered formalin and were then paraffin embedded. Sections were cut to $4 \mu \mathrm{m}$ and stained with hematoxylin-eosin and periodic acid-Schiff. Additional $4-\mu \mathrm{m}$ sections on L-lysine-coated slides were used for immunohistochemical studies using an avidin-biotin-pcroxidase technique with commercially available antibodies for glial fibrillary acidic protein (GFAP) (Dako, Carpinteria, CA; diluted 1:1,000), high molecular weight keratin (K576, Dako, diluted 1:500), and low molecular weight keratin (Cam 5.2, Becton-Dickinson, Mountain View, CA; diluted 1:10). Immunohistochemical stains for progesterone and estrogen receptor proteins ${ }^{4}$ (Abbott, Chicago, IL; diluted 1: 2) were performed using an alkaline phosphatase technique.

\section{PATHOLOGY}

The right and left ovaries measured 14 and $16 \mathrm{~cm}$ in greatest dimension, respectively, and each had a capsule marked by papillary excrescences. On cut section each was predominantly multicystic, with cyst diameters ranging from 1 to $10 \mathrm{~cm}$ bilaterally (Fig 1). Papillary excrescences were grossly visible on the inner surfaces of many of the cysts. The uterus, cervix, and fallopian tubes had multiple serosal implants of 1 to $2 \mathrm{~mm}$. Hepatic and splenic biopsy specimens consisted of thin-walled cysts less than $2 \mathrm{~cm}$ in diameter, as well as fragments of friable tan tissue. Histologically, all of the areas of neoplastic involvement were composed of sheets of uniform, spindled to columnar cells with pink cytoplasm and regular, round to ovoid nuclei. Occasional ciliated cells were present. In many foci round and tubular-shaped rosettes were formed by neoplastic cells (Fig 2). In addition, vascular pseudorosettes were present and consisted of thin-walled blood vessels surrounded by cells with antipodally arranged nuclei and radiating fibrillary processes that tapered toward the vascular lumen. Nithough occasional papillac were present, no psammoma bodies were identified. Mitotic figures were not identified. Vascular invasion and areas of necrosis were present in both ovarian neoplasms. No derivatives of other germ cell layers were identified. Subsequent biopsy specimens obtained at second-look laparotomy contained cells with identical histologic features in irregular nests surrounded by fibrous tissue. Rosette formation was infrequent in the recurrent neoplasm. Perito-
FIGURE 1. Sections of multicystic left and right ovarian ependymomas (shown on left and right, respectively) with focal excrescences on the surface and in the lining of some cysts.

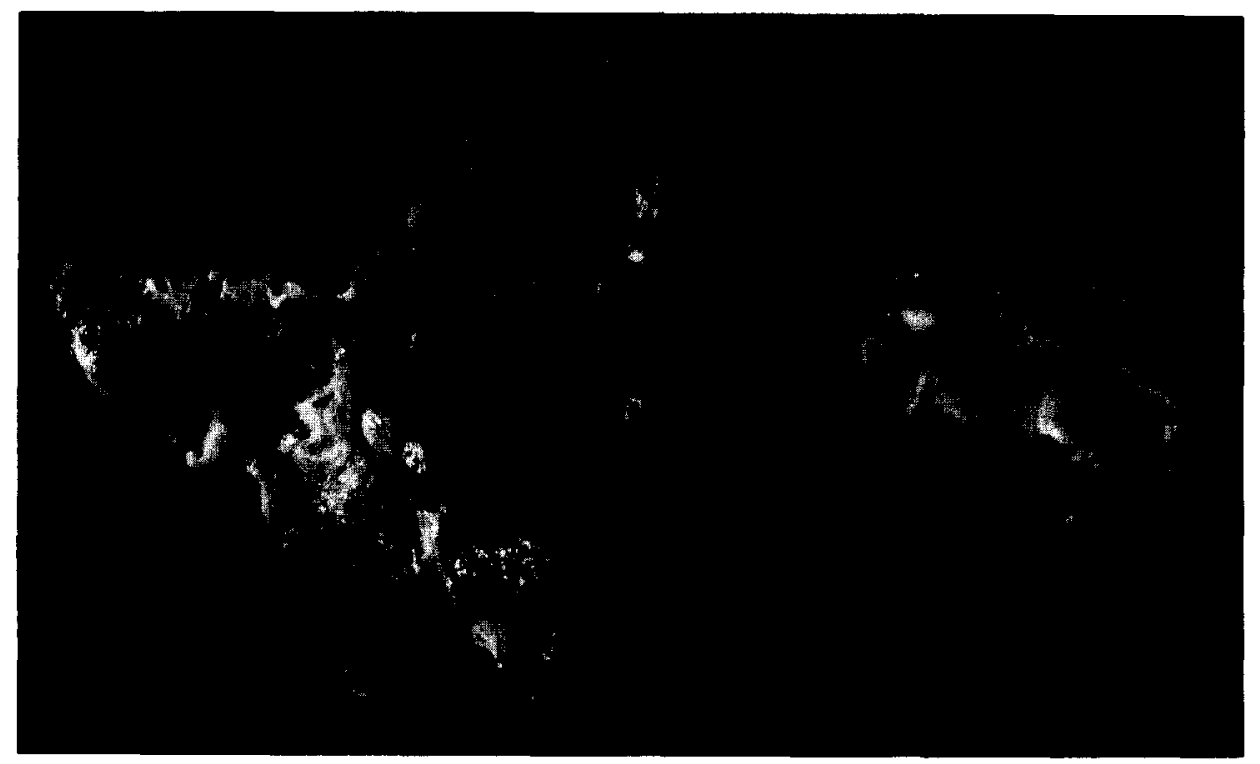




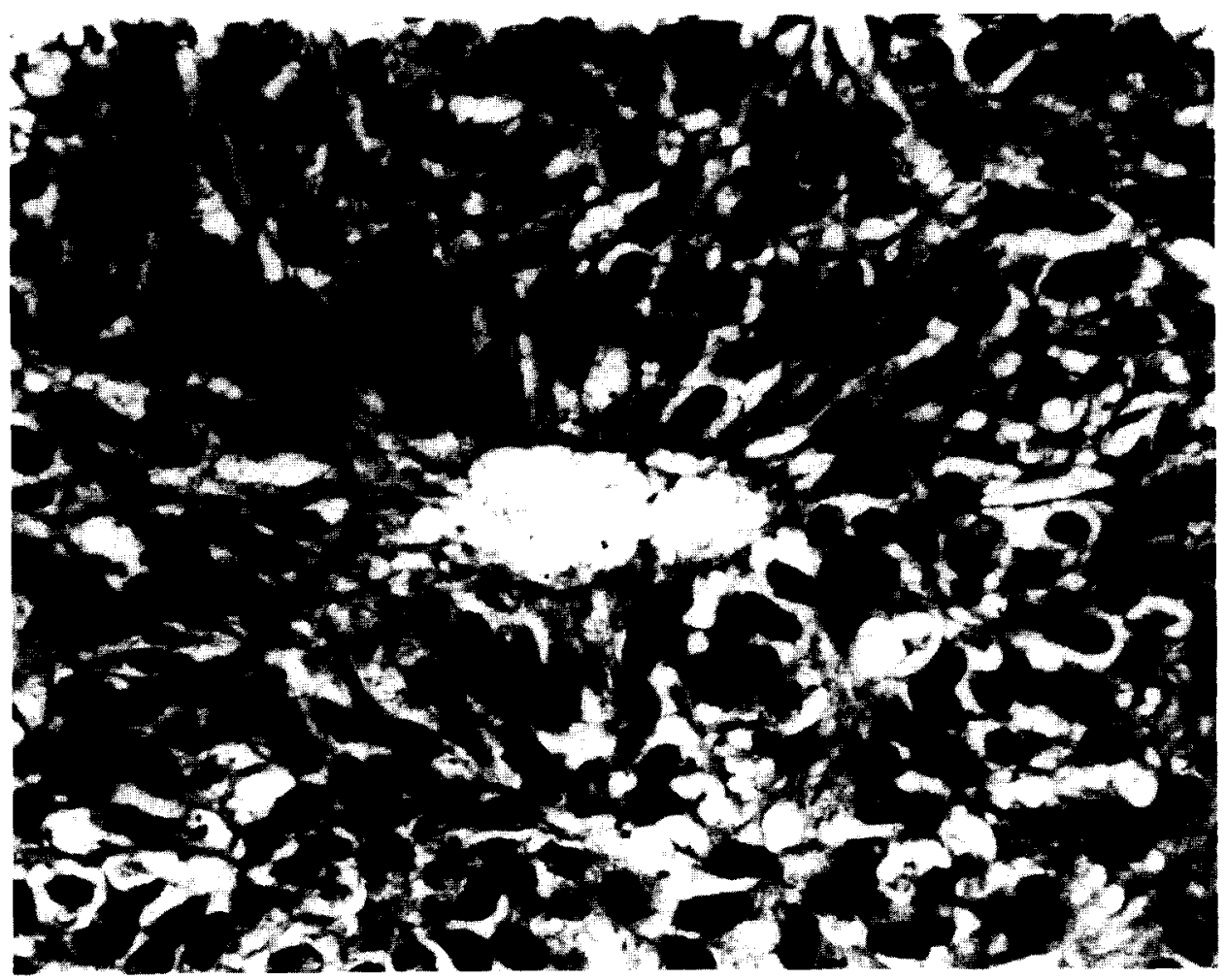

FICURE 2. Rosette formation by tumor cells. (Hematoxylin-eosin stain; magnification $\times 400$.)

neal washings obtained at the time of second-look laparotomy were positive for neoplasm. Both primary and recurrent neoplastic cells stained diffusely positive for GFAP (Fig 3), but not for low or high molecular weight cytokeratins. In addition, immunohistochemical stains for progesterone receptor showed areas of strong nuclear staining in both primary and recurrent neoplasms (Fig 4). No staining for estrogen receptor protein was seen.

\section{DISCUSSION}

This represents the fourth reported case of an ependymoma of the ovary and the first case with bilateral involvement. The ovaries in this case, at 14 and $16 \mathrm{~cm}$ in size, were larger than previously reported $(1.0$ to $13.0 \mathrm{~cm}) .^{2}$ Of the three previously reported cases of this rare entity, two patients presented with stage III disease and one with stage I disease. The patient

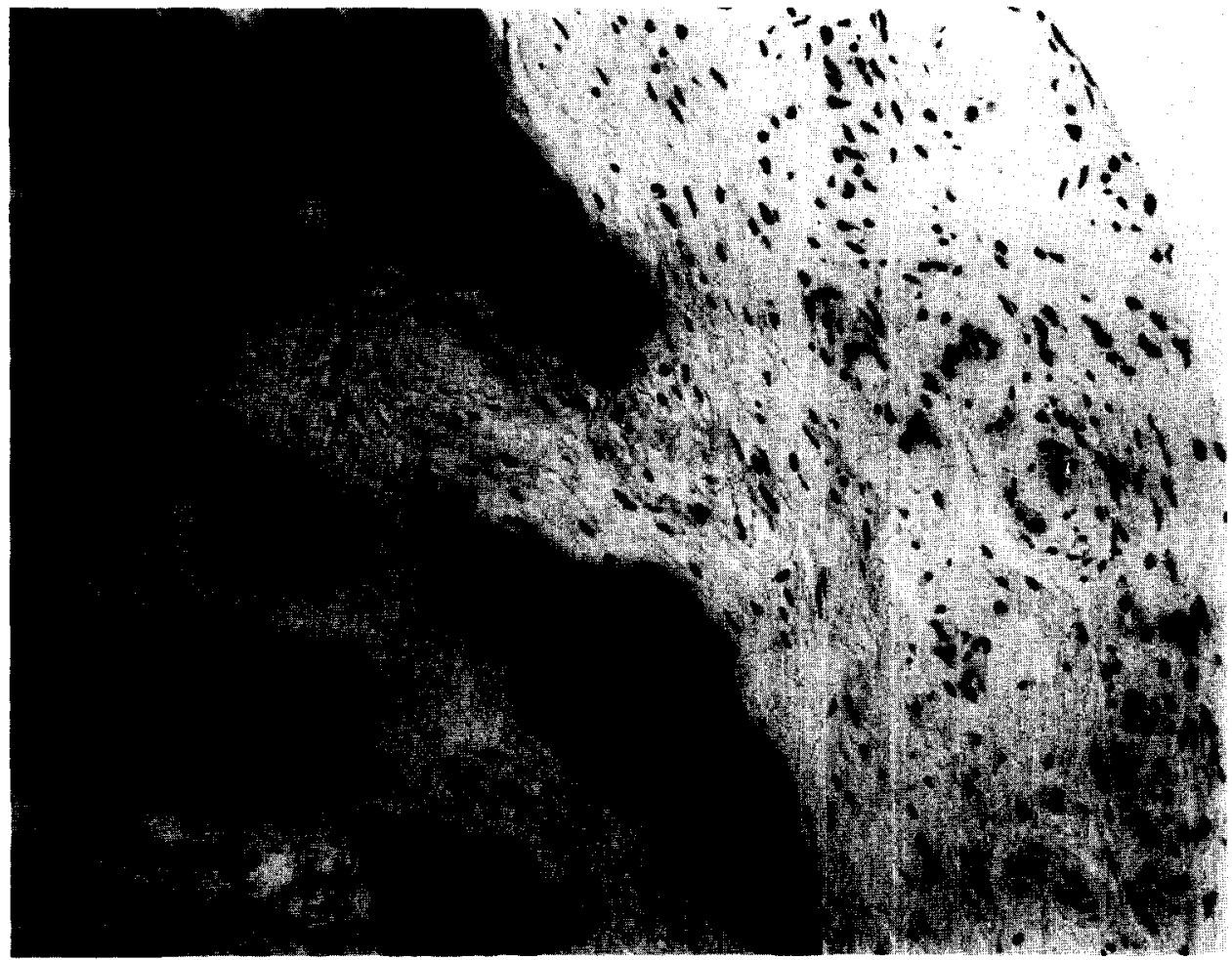

FICURE 3. Glial fibrillary acidic protein in appendiceal implants of recurrent ovarian ependymoma. (Immunohistochemical stain; magnification $\times 200$.) 
FICURE 4. Positive staining for progesterone receptor in the nuclei of tumor cell nests was seen in recurrent (as well as primary) ependymoma. Note abortive rosette formation by the tumor cells. (Immunohistochemical stain; magnification $\times 400$.)

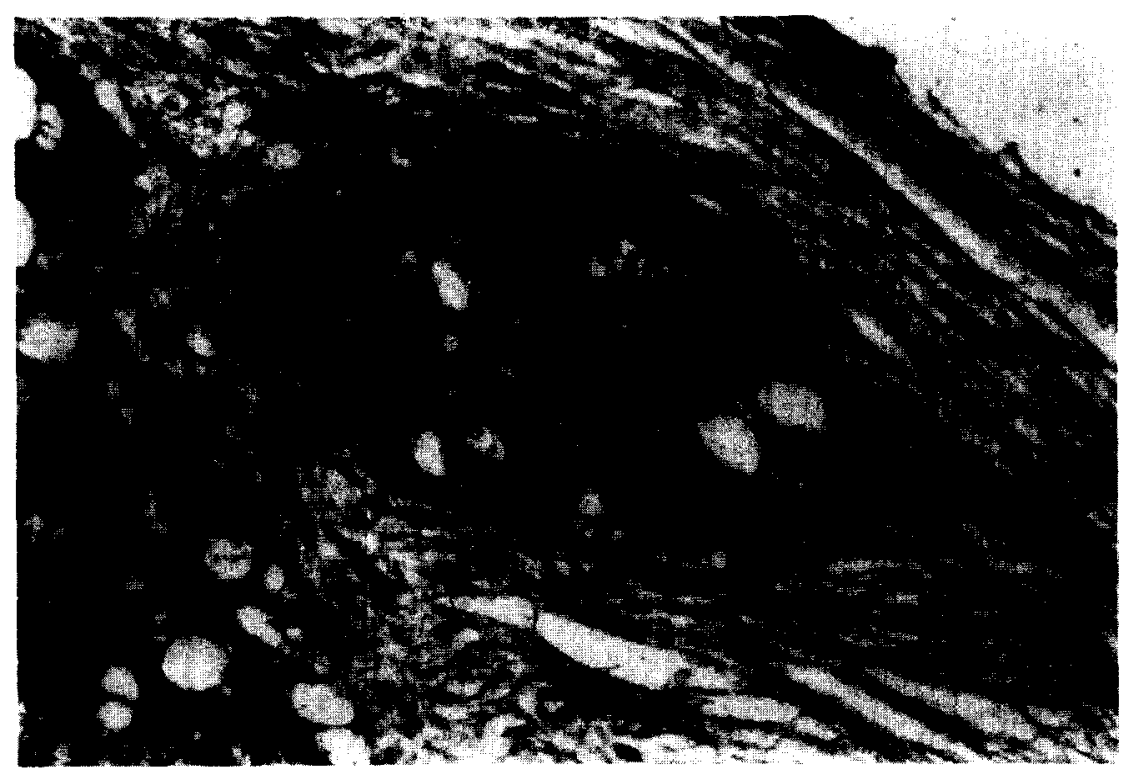

with stage I presentation was alive with no evidence of disease 5 years later. Of the two patients with stage III disease, one died of disease as originally reported. The other patient with advanced disease was subsequently re-reported when the tumor recurred 5 years later while she was receiving replacement estrogen and progestin replacement therapy. ${ }^{3}$ The recurrent neoplasm was found to be positive for cytosolic estrogen and progesterone receptors, and after cessation of hormonal replacement the patient has remained disease free. The case presented here is the first with bilateral ovarian involvement as well as the first to present as stage IV disease. The extent of this tumor at term pregnancy along with the finding of progesterone receptors in the neoplasm are very suggestive that the tumor's growth was influenced by hormonal factors. This is not unique to those ependymomas that occur in the female genital tract; progesterone (and estrogen) receptors have been reported in ependymomas ${ }^{5}$ and other primary neoplasms of the spinal cord ${ }^{6}$ and are thought to account for the rapid clinical course of some spinal cord tumors in the luteal phase of the menstrual cycle and during pregnancy. ${ }^{7}$

The histologic feature that most facilitated the diagnosis in this case was the prominence of rosettes and perivascular pseudorosettes. With positive immunohistochemical staining for GFAP, this cellular pattern is quite characteristic of an ependymoma. ${ }^{8}$ Other histologic features of this case were consistent with those of the previously reported cases of ovarian ependymoma. ${ }^{2}$ Psammoma bodies were noted in two reported cases of ependymoma of the broad ligament, ${ }^{9}$ but they were not identified in our case nor were they seen in the three cases of ovarian ependymoma originally reported. As reviewed in that report, ${ }^{2}$ the differential diagnosis of this neoplasm includes serous and endometrioid tumors due to the presence of papillae. In fact, the biopsy specimens from this lesion were initially submitted with a diagnosis of papillary adenocarcinoma. However, the identification of the features described above, especially in conjunction with immunohistochemical stains for GFAP, ensures the correct diagnosis.

The histogenic origin of extraspinal ependymomas may vary with location. Extramedullary ependymomas also have been reported in the subcutaneous tissue of the sacrococcygeal region, ${ }^{10}$ adjacent to the sacrum, ${ }^{11}$ and in the mediastinum. ${ }^{12}$ In the sacrococcygeal region these tumors are thought to arise from heterotopic ependymal cell rests or from the coccygeal medullary vestige. ${ }^{10,11}$ Previous reports of ependymomas of the female genital tract include three cases in the ovary, ${ }^{2}$ two in the broad ligament, ${ }^{9}$ and one in the mesovarium. ${ }^{13}$ No ependymal islands, per se, are thought to exist in these locations. Like other neuroectodermal tumors of the ovary, ependymal neoplasms arising in the ovary are believed to represent monodermal teratomas. ${ }^{2}$ In contrast, ependymomas of the broad ligament have been postulated to arise from neometaplasia of mesenchymal cells. ${ }^{9}$ The origin of ependymomas of mediastinum and mesovarium is unclear. ${ }^{12,13}$

Acknowledgment. The authors gratefully acknowledge Dr Robert Schmidt for initially reviewing this case, Dr Robert Scully for generously reviewing this case and providing clinical follow-up of his earlier reported cases, and the Immunoperoxidase Laboratory of the University of Michigan for providing technical assistance.

\section{REFERENCES}

1. Aguirre P, Scully RE: Malignant neuroectodermal tumor of the ovary, a distinctive form of monodermal teratoma. Report of five cases. Am J Surg Pathol 6:283-292, 1982

2. Kleinman G, Young R, Scully RE: Ependymoma of the ovary: Report of three cases. Hum PATHOL. 15:632-638, 1984

3. Auerbach R, Mittal K, Schwartz PE: Estrogen and progestin receptors in an ovarian ependymoma. Obstet Gynecol 71:1043-1045, 1988

4. Cheng L, Binder S, Fu Y, et al: Demonstration of estrogen receptors by monoclonal antibody in formalin-fixed breast tumors. Lab Invest 58:346353,1988

5. Concolino G, Giuttre R, Margiotta G, et al: Steroid receptors in CNS: Estradiol (ER) and progesterone (PR) receptors in human spinal cord tumors. J Steroid Biochem 20:491-494, 1984

b. Cahill DW, Bashirelahi N, Solomon LW, et al: Estrogen and progesterone receptors in meningiomas. J Neurosurg 60:985-993, 1984

7. Mealey J, Jr, Carter JE: Spinal cord tumor during pregnancy. Obstet Gynecol 32:204-209, 1968

8. Velasco ME, Dahl D, Roessmann U, et al: Immunohistochemical localization of glial fibrillary acidic protein in human glial neoplasms. Cancer 45 484-494, 1980

9. Bell DA, Woodruff JM, Scully RE: Ependymoma of the broad ligament. A report of two cases. Am J Surg Pathol 8:203-209, 1984

10. Anderson MS: Myxopapillary ependymomas presenting in the soft tissuc over the sacrococcygeal region. Cancer 19:585-590, 1966

11. Morantz RA, Kepes JJ, Batnitzky S, et al: Extraspinal ependymomas. Report of thrce cascs. J Ncurosurg 51:383-391, 1979

12. Nobles E, Lee R, Kircher T: Mediastinal ependymoma. HuM PATHOL 22:94-96, 1991

13. Grody WW, Nieberg RK. Bhuta S: Ependymoma-like tumor of the mesovarium. Arch Pathol Lab Med 109:291-293, 1985 